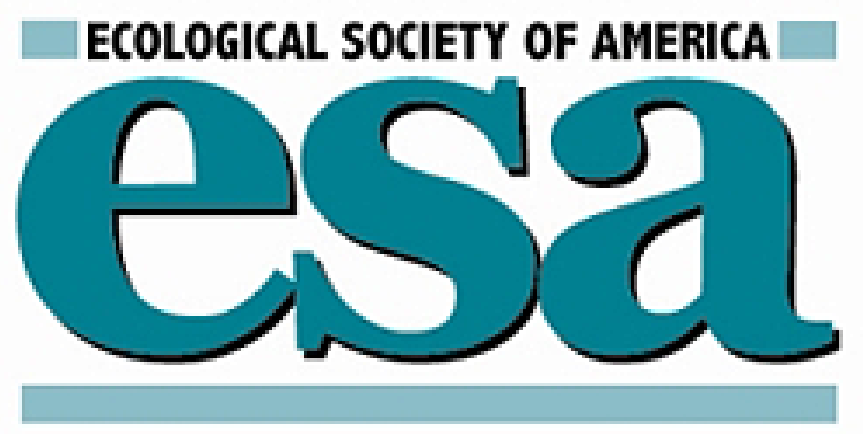

Living Close, Doing Differently: Small-Scale Asynchrony in Demography of Two Species of Seabirds

Author(s): Giacomo Tavecchia, Eduardo Minguez, Ana De León, Maite Louzao and Daniel Oro Source: Ecology, Vol. 89, No. 1 (Jan., 2008), pp. 77-85

Published by: Ecological Society of America

Stable URL: http://www.jstor.org/stable/27651510

Accessed: 27/06/2014 07:52

Your use of the JSTOR archive indicates your acceptance of the Terms \& Conditions of Use, available at http://www.jstor.org/page/info/about/policies/terms.jsp

JSTOR is a not-for-profit service that helps scholars, researchers, and students discover, use, and build upon a wide range of content in a trusted digital archive. We use information technology and tools to increase productivity and facilitate new forms of scholarship. For more information about JSTOR, please contact support@jstor.org. 


\title{
LIVING CLOSE, DOING DIFFERENTLY: SMALL-SCALE ASYNCHRONY IN DEMOGRAPHY OF TWO SPECIES OF SEABIRDS
}

\author{
Giacomo Tavecchia, ${ }^{1,2,5}$ Eduardo Minguez, ${ }^{3}$ Ana De León, ${ }^{4}$ Maite Louzao, ${ }^{1}$ and Daniel Oro ${ }^{1}$ \\ ${ }^{1}$ Institut Mediterrani d'Estudis Avançats (IMEDEA), CSIC-UIB, Miquel Marques 21, Esporles, Mallorca 07190 Spain \\ ${ }^{2}$ Institute of Mathematics, Statistics and Actual Science, University of Kent, Canterbury CT2 7NZ United Kingdom \\ ${ }^{3}$ Universidad Miguel Hernandez, Avda. de la Universidad s/n, Edif. Torreblanca, Elche, Alicante 03202 Spain \\ ${ }^{4}$ Ornithology Group, IBLS, Graham Kerr Building, University of Glasgow, Glasgow G128QQ United Kingdom
}

Abstract. Studies on spatiotemporal pattern of population abundance predict that close populations should exhibit a high level of synchrony, reflected in a parallel time variation of at least one demographic parameter. We tested this prediction for two threatened species of Procellariiformes sharing similar life history traits: the European Storm Petrel (Hydrobates pelagicus) and the Balearic Shearwater (Puffinus mauretanicus). Within each species, we compared adult survival, proportion of transients (breeders that do not settle), and average productivity at two neighboring colonies. Physical and environmental features (e.g., food availability) of the breeding sites were similar. However, while Balearic Shearwater colonies were free of predators, aerial predators occurred especially in one colony of the European Storm Petrel. Despite this difference, we found similar results for the two species. A high proportion of transient birds was detected in only one colony of each species, ranging between $0.00-0.38$ and $0.10-0.63$ for the petrels and shearwaters, respectively. This seems to be an emergent feature of spatially structured populations of seabirds, unrelated to colony size or predator pressure, that can have important demographic consequences for local population dynamics and their synchrony. Local survival of resident birds was different at each colony, an unexpected result, especially for predator-free colonies of Balearic Shearwater. Productivity varied between the two colonies of European Storm Petrels, but not between the two colonies of Balearic Shearwaters. We demonstrated that within each species, several demographic parameters were colony specific and sufficiently different to generate short-term asynchronous dynamics. Our findings suggest that, in spatially structured populations, local factors, such as predation or small-scale habitat features, or population factors, such as individual quality or age structure, can generate unexpected asynchrony between neighboring populations.

Key words: adult survival analysis; Balearic Shearwater; capture-recapture; demography; European Storm Petrel; Hydrobates pelagicus; population synchrony; Procellariiformes; Puffinus mauretanicus; seabirds.

\section{INTRODUCTION}

The degree of synchrony between the different demes of spatially structured populations is an important determinant of their persistence and much attention has been devoted to factors underpinning betweenpopulation synchrony (see review in Bjørnstad et al. 1999, Lloyd and May 1999). Moran (1953) showed that the degree of synchrony between two identical systems should equal the degree of correlation between their environments, usually measured by climatic variations (Lande et al. 2003). Empirical evidence of the Moran effect can be found in different taxa (Grenfell et al. 1998; but see Blasius and Stone 2000, Ruetz et al. 2005). In addition to environmental correlation, synchronous

Manuscript received 24 February 2006; revised 16 February 2007; accepted 26 March 2007; final version received 30 May 2007. Corresponding Editor: J. R. Sauer.

5 Address for correspondence: Institut Mediterrani d'Estudis Avançats (IMEDEA), CSIC-UIB, Miquel Marques 21, Esporles, Mallorca 07190 Spain. E-mail: g.tavecchia@uib.es population dynamics also can be induced by parameters such as density-dependent dispersal (Sutcliffe et al. 1996, Paradis et al. 1999). Environmental and dispersal effects are difficult to disentangle (Ranta et al. 1995), but the expected pattern of synchrony is different: although individual dispersal generates a negative correlation between the degree of synchrony and interpopulation distance, climate-induced synchrony is less dependent upon the distance considered (Stenseth et al. 1999). Finally, biotic interactions (such as predator-prey and host-parasitoid systems) also can induce synchrony in population dynamics (Ims and Andreassen 2000, Liebhold et al. 2004a, b).

A general consensus is that the relative roles of climate, dispersal, and predation in shaping synchrony largely depend on the spatial scale and that synchrony is negatively associated with distance (Koenig 1999, Lloyd and May 1999). Climate is the dominant cause of synchrony at a large spatial scale, whereas predation or between-population movements are more likely to act at a medium or small scale (Ranta et al. 1995), depending 
upon the species dispersal ability (Paradis et al. 1999). Even if these causes act synergistically and are difficult to disentangle, climatic variation and movements generate two implicit predictions regarding synchrony. First, whatever the cause, two neighboring populations should show synchronous dynamics and this should be more evident in species with high dispersal ability (Paradis et al. 1999). Individuals of close populations are more likely to experience the same weather regime, a relatively high exchange probability, and a similar predator pressure, characteristics positively associated with between-population synchrony. Second, the mechanistic explanation of synchronous dynamic is a parallel fluctuation over time between the demographic parameters of the populations (Cattadori et al. 2005). Synchrony measures derived by the analysis of population counts fail to elucidate the mechanisms underlying parallel fluctuations. For this reason, recent studies tend to focus directly on the variation of demographic parameters using detailed information on individual life histories (Lecomte et al. 2004, Cattadori et al. 2005, Frederiksen et al. 2005, Harris et al. 2005, Schaub et al. 2005). Evidence of synchronous dynamics can thus be derived by the timedependent pattern of demographic parameters, although the parallel fluctuation of one or more of them is a necessary, but not sufficient, condition for synchrony to occur. Moreover this approach is recommended when population abundances are not available or when large sampling errors are associated with them.

We analyzed the synchronous pattern of demographic parameters in two neighboring colonies of two threatened seabirds: the European Storm Petrel (Hydrobates pelagicus) and the Balearic Shearwater (Puffinus mauretanicus). Despite differences in body mass (average $45 \mathrm{~g}$ for Storm Petrels and $500 \mathrm{~g}$ for Shearwaters) and foraging niche, the two species share many life history traits: a relative long life span and low fecundity, a cavity-nesting habit and high breeding-site fidelity (Warham 1990, Mínguez and Oro 2003, Oro et al. 2005). The definition and measures of population synchrony are not consistent in the ecological literature (Vik et al. 2004). Here we tested the hypothesis that two colonies in close proximity, sharing the same ecological features, are fluctuating synchronously in time, as predicted by the Moran effect and the generally accepted negative association between distance and synchrony. Because it is notoriously difficult to estimate population abundances for these species, evidence of population synchrony can be achieved only by assessing the parallel time oscillation in least one demographic parameter. The population growth rate of long-lived species is more sensitive to a change in adult survival probability (Lebreton and Clobert 1991), suggesting that parallel oscillations of populations can result from a synchronous change in this parameter. On the other hand, natural selection tends to reduce the temporal variation of the parameter that contributes the most to individual fitness (Gaillard and Yoccoz 2004, Morris and Doak
2004), and observed changes in population growth rate can be driven primarily by a change in fecundity parameters. As a consequence we considered for each species adult survival probability, transient probability (probability of breeding only once) and breeding parameters (hatching success and fledgling success). Numerically, we expect to retain a time effect on one or all of these parameters and to drop the statistical interaction between the "colony" and "time" effects.

To confirm that the dynamics of the study colonies were synchronous, we then estimated the correlation between the colony-specific population growth rates over time (Bjørnstad et al. 1999, Vik et al. 2004), using a matrix population model. We used this approach because an asynchronous fluctuation in demographic parameters is a necessary, but not a sufficient, condition for asynchronous dynamics. This is because the variance of a given demographic parameter is negatively associated with the relative contribution of this parameter to population change, i.e., its sensitivity (Pfister 1998). As a consequence, the variation of a parameter over time does not necessary result in a change in the population growth rate.

\section{Methods}

Study sites and species

Data for European Storm Petrels were collected during 1993-2002 in two neighboring colonies at Benidorm Island on the western Mediterranean coast of Spain $\left(38^{\circ} 30^{\prime} \mathrm{N}, 0^{\circ} 8^{\prime} \mathrm{E}\right.$; Fig. 1). The sites were very close $(150 \mathrm{~m})$, but their size varied markedly: one colony, hereafter $A_{p}$ (the subscripts $p$ and s indicate parameters for Storm Petrels and Balearic Shearwaters, respectively), was a large cave containing an estimated population of more than 200 pairs, while the second colony, $B_{p}$, was smaller in size and had an estimated population of about 100 pairs (see also Oro et al. 2005). Despite their proximity, there has been only one record of adult dispersal between the two sites in a 10 -year period. The effect of Yellow-legged Gulls Larus michahellis preying on adult birds arriving at the sites has apparently increased during the last years, mainly on colony $A_{p}$ (Oro et al. 2005).

For Balearic Shearwaters, two colonies of the southwestern coast of Mallorca Island $\left(39^{\circ} 31^{\prime} \mathrm{N}, 2^{\circ} 23^{\prime}\right.$ E; Fig. 1) were monitored during the period 1997-2004. The sites were $15 \mathrm{~km}$ apart, a short distance considering the large foraging range of the species $\left(\sim 40000 \mathrm{~km}^{2}\right.$; Arcos and Oro 2004). One of the colonies, colony $A_{s}$ hereafter, had an estimated size of $\sim 200$ pairs; the other, $\mathrm{B}_{\mathrm{s}}$, was smaller ( $\sim 45$ pairs) (Oro et al. $\left.2004 a\right)$. There have been no cases of dispersal recorded during the eight-year period of the study and both colonies were free of predators during the study period.

\section{Adult survival and transient parameters}

Adults were captured during the incubation period or just after egg hatching at the nest and were marked using 


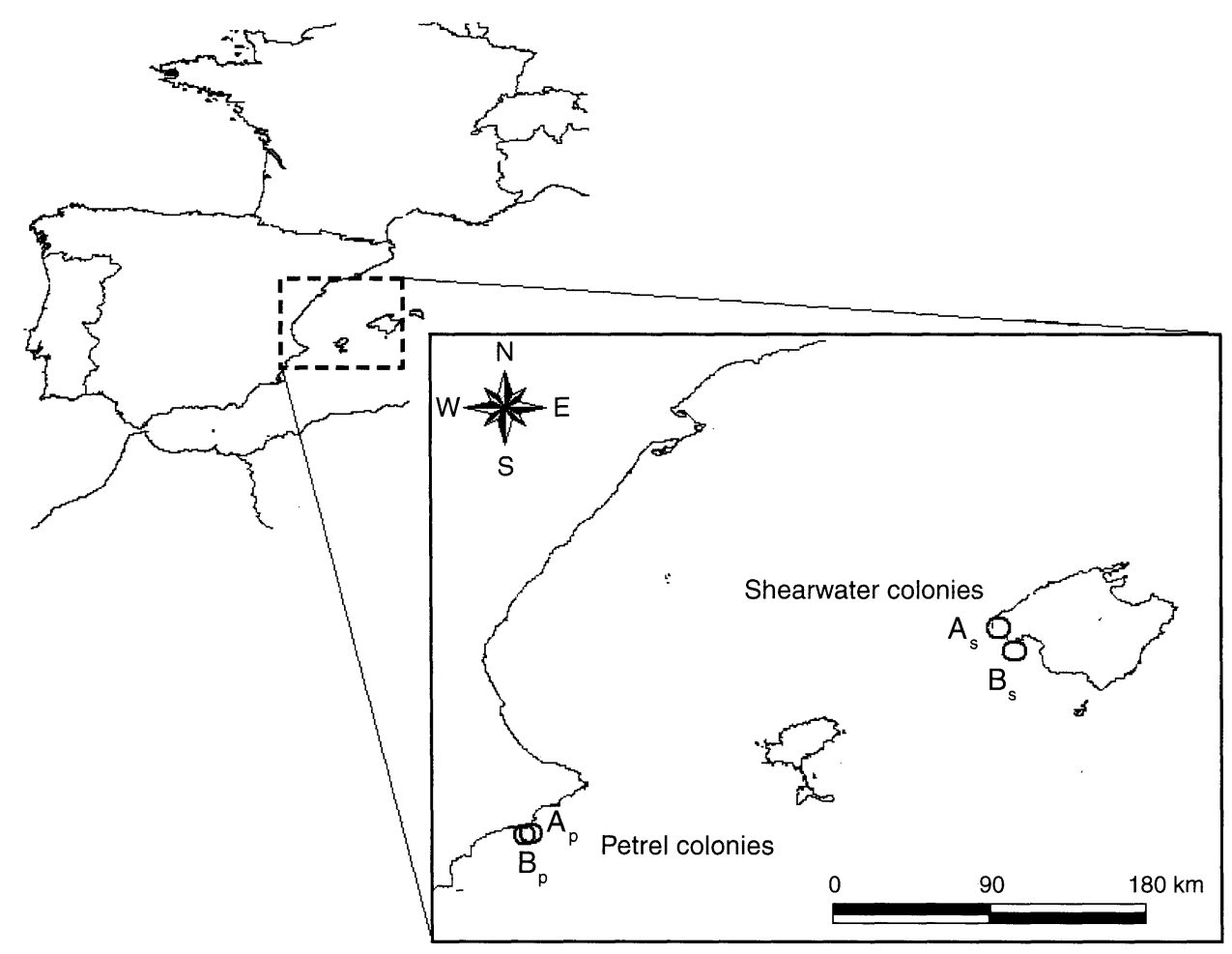

FIG. 1. Colony locations of the European Storm Petrel Hydrobates pelagicus $\left(\mathrm{A}_{\mathrm{p}}, \mathrm{B}_{\mathrm{p}}\right)$ and Balearic Shearwater Puffinus mauretanicus $\left(\mathrm{A}_{\mathrm{s}}, \mathrm{B}_{\mathrm{s}}\right)$ in the western Mediterranean.

a uniquely coded metal ring (see details in Oro et al. 2004a, 2005). We analyzed the encounter histories of 627 breeding European Storm Petrels and 573 Balearic Shearwaters (474 and 153 in colonies $A_{p}$ and $B_{p}$ and 321 and 252 in colonies $A_{s}$ and $B_{s}$, respectively). Adult local survival estimates were obtained by maximum likelihood procedure from individual encounter histories using software MARK version 1.9 (White and Burnham 1999). This approach does not distinguish mortality from permanent emigration, and survival includes an emigration component. Model selection started from the general model assuming a colony-by-year interaction on survival and recapture parameters, noted $\{\phi[(c+t+c . t)$ $p(c+t+c . t)]\}$, where $t$ denoted a year effect, $c$ a colony effect, and t.c denoted their statistical interaction. If populations showed parallel fluctuations in survival probabilities, i.e., synchrony, t.c would not be retained.

We contrasted models with and without temporal variability and the colony-by-time interaction term in order to calculate the fraction of the total temporal deviance explained by a common pattern of variation as in Harris et al. (2005). The goodness of fit of the general model was tested by contingency tables (see Appendix A) using program U_CARE1.4 (Choquet et al. 2000). The goodness-of-fit test sums the results of four sets of contingency tables, traditionally named test3.SR, test3.SM, test2.CT, and test2.CL, built for each time interval (Pollock et al. 1990, Pradel et al. 2005; see Appendix A). Choquet et al. (2005) proposed directional tests ( $Z$ tests) designed to detect systematic deviations from the expected values in the contingency tables of test3.SR and test2.CT. A significant $Z$ value on test3.SR suggests a difference in local survival between newly and already marked birds, an effect known as "transience" (Pradel et al. 1997a). A significant $Z$ value on test2.CT indicates a difference in recapture probability in relation to previous capture, an effect known as "trap dependence" (Pradel 1993; see Appendix A). Both effects were significant in at least one species (see Results). The presence of transients was taken into account by considering extra survival parameters for newly seen individuals, noted $\phi^{\prime}$ (Pradel et al. 1997a, Oro et al 1999, Perret et al. 2003). Note that here transient birds are not erratic or prospecting individuals, but birds that bred at the colony once and were never seen again. The transient probability (noted by $\tau$ ) can be estimated as

$$
\tau_{i}=1-\frac{\phi_{i}^{\prime}}{\phi_{i}}
$$

where $\phi_{i}^{\prime}$ is the survival rate for newly seen individuals, and $\phi_{i}$ that for residents. Confidence intervals for $\tau$ can be calculated using the Delta method (Morgan 2000). The trap-dependence effect was corrected for by coding capture histories, as suggested in Pradel (1993) and Pradel et al. (1997b). The remaining extra-binomial variation was taken into account by scaling model deviances by a variance inflator factor, $\hat{c}$, calculated as 
the ratio of the $\chi^{2}$ goodness of fit to its degrees of freedom (Lebreton et al. 1992).

\section{Breeding parameters}

Data on breeding success for the two species were collected by inspecting nests throughout the breeding season. We analyzed the breeding success of 286 nests of European Storm Petrels between 1993 and 2002 (2059 monitored nests in total), and of 136 nests of Balearic Shearwaters between 1997 and 2004 (672 monitored nests in total). We restricted the analysis to active nests only, i.e., where an egg was laid. Nests were followed from the beginning of the laying period until the end of the fledging period. During subsequent visits (an average of five visits per nest and year), we recorded whether the egg hatched and whether the chick survived, i.e., when it reached the fledging age at the end of the breeding season (40 days for European Storm Petrels, 60 days for Balearic Shearwaters). Differentiating egg failure from hatching mortality was simple in the absence of nest predators in all study colonies, and remains of eggs or chicks were easily found in the nest cavities. We first analyzed overall breeding success, i.e., the probability that an egg would produce a fledging bird. Subsequently, we split breeding success into its two components, namely the hatching success (the probability that an egg will hatch) and the fledging success (the probability that a chick will stay alive until fledging), which in our singleegg study species equated to the number of fledglings per breeding pair. These probabilities were modeled as binomial responses using generalized linear models (software GENSTAT version 7.1; Lawes Agricultural Trust, Rothamsted, UK). Note that the Mayfield method was not applicable here because all nests were monitored from the beginning of the laying phase, and because, in Procellariiformes, the incubation period may vary from nest to nest (Williams et al. 2002).

We investigated which component of breeding success varied the most by measuring the relativized coefficient of variation, $\mathrm{CVr}$, for zero-to-one variables. $\mathrm{The} \mathrm{CVr}$ is the ratio between the coefficient of variation and its maximum expected value (Morris and Doak 2004). This measure is preferable to the simple coefficient of variation: the variance and the coefficient of variation of zero-to-one variables are truncated because they cannot have high mean and high variance at the same time (Morris and Doak 2004). We used a subsample of 702 nests of European Storm Petrels in which male and females were identified to test whether the heterogeneity in breeding parameters between pairs was significant, considering pair identity as a random effect in a generalized linear mixed model (IRREML [iterated reweighted restricted maximum likelihood] models in GENSTAT version 7.1). Pair identity was not significant; hence, we treated observations from the same pair in consecutive years as independent. For the Balearic Shearwater, data were too sparse to perform a similar analysis and multiple observations of the same pair were assumed to be independent. We tested the effect of year $(t)$, of the colony $(c)$, and their statistical interaction (t.c). As before, if populations were to show parallel fluctuations in breeding parameters, i.e., synchrony, the term $t \cdot c$ would not be significant. To account for model selection uncertainty, model-averaged estimates were presented.

\section{Model selection}

Model selection and notation were the same in the analyses of survival and breeding parameters. Once we had accounted for the heterogeneity, we eliminated nonsignificant effects from the general model. Models were compared using Akaike's Information Criterion, AIC (Burnham and Anderson 1998), and were arbitrarily considered equivalent when their values were within 4 points (Burnham and Anderson 1998:123) When this occurred, we retained the most parsimonious model, i.e., the one with the smallest number of parameters. The AIC was denoted as QAIC when an overdispersion parameter was used to scale model deviances, and $\triangle$ QAIC was the difference in QAIC between the model tested and the model finally selected. Finally, the AIC was corrected for small sample size $\left(\mathrm{AIC}_{\mathrm{c}}\right)$ in the adult survival analysis (Burnham and Anderson 1998).

\section{Population modeling}

To investigate whether the colony-specific differences were large enough to create asynchronous dynamics, we constructed simple deterministic matrix population models for each colony based on parameter values estimated in the present study. The dominant eigenvalue of matrix $\boldsymbol{A}_{i}^{j}$ was taken as the population growth rate between time $i$ and $i+1$ (see Appendix C; Case 2000, Caswell 2001). Under the hypothesis of synchronous dynamics between the two colonies of each species, we expected a significant correlation between their respective population growth rates. For adults, we used timespecific parameters in the matrices if temporal variability was proved to be significant. Individuals of both species start to reproduce at the age of 3 years (Oro et al. $2004 b$ ), but survival estimates for the pre-breeding period are unknown. Hence, for immature birds we assumed the average value of adult survival. The hypothesis of a constant pre-breeding survival equal to the survival of adult birds is likely to be unrealistic, but it is conservative when testing for a correlation between colony-specific population growth rates. A more robust approach to estimating population growth rate using capture-recapture data (Pradel 1996) was not possible in our case because recruitment parameters could not be estimated (only adults were marked). The matrix-based population growth rate does not necessary reflect the true increase in population size because it does not account for immigration and is based on the unrealistic assumption of a stable age structure. Moreover, our aim was not to model the actual dynamics but to synthesize the demographic information by period for comparison. 
TABLE 1. Components of the goodness-of-fit test of the general model assuming year-by-colony-specific parameters at two colonies (A, larger; B, smaller) for each species.

\begin{tabular}{|c|c|c|c|c|c|c|c|c|c|c|c|c|}
\hline \multirow[b]{3}{*}{ Component } & \multicolumn{6}{|c|}{ European Storm Petrel } & \multicolumn{6}{|c|}{ Balearic Shearwater } \\
\hline & \multicolumn{3}{|c|}{$A_{p}$} & \multicolumn{3}{|c|}{$\mathrm{B}_{\mathrm{p}}$} & \multicolumn{3}{|c|}{$\mathrm{A}_{\mathrm{s}}$} & \multicolumn{3}{|c|}{$\mathrm{B}_{\mathrm{s}}$} \\
\hline & $\chi^{2}$ & df & $Z$ & $\chi^{2}$ & df & $Z$ & $\chi^{2}$ & df & $Z$ & $\chi^{2}$ & df & $Z$ \\
\hline Test3.SR & 29.2 & 8 & 2.8 & 14.7 & 7 & 1.1 & 6.9 & 6 & 0.0 & 31.6 & 10 & 2.0 \\
\hline Test3.SM & 9.7 & 8 & & 7.7 & 6 & & 3.6 & 5 & & 7.1 & 6 & \\
\hline Test2.CT & 77.1 & 7 & -7.9 & 7.0 & 6 & -2.0 & 7.3 & 5 & -1.6 & 4.9 & 6 & -0.4 \\
\hline Test2.CL & 17.3 & 8 & & 1.2 & 4 & & 6.1 & 5 & & 0 & 1 & \\
\hline
\end{tabular}

Notes: The first two components, test3.SR and test3.SM, test for among-individual homogeneity in survival; test2.CT and test2.CL test for homogeneity in recapture processes (Pollock et al. 1990, Choquet et al. 2005; Appendix A). $Z$ statistics on test3.SR and test.2CT, respectively, are used to test for the presence of transients (animals seen only once) and for a trap-dependence effect (i.e., current capture probability is influenced by previous capture history); see Appendix A. Significant tests are in boldface. For the petrel, colony $A_{p}$ contained $>200$ pairs, and colony $B_{p}$ contained $\sim 100$ pairs. For the shearwater, colony $A_{s}$ contained $\sim 200$ pairs, and colony $\mathrm{B}_{\mathrm{s}}$ contained $\sim 45$ pairs.

In this case, the matrix-based population growth can give an indication of the deterministic growth rate according to the parameters used in the model.

\section{RESULTS}

\section{Adult survival parameters}

The goodness-of-fit test of the first model $\{\phi(t+c+$ t.c) $p(t+c+t . c)\}$ was significant for both species $\left(\chi^{2}=\right.$ 163.8, df $=54, P<0.001$ and $\chi^{2}=67.4, \mathrm{df}=54, P=$ 0.017 ; Table 1), hence, this first model did not explain the data adequately. This was due to the presence of transients in colonies $A_{p}$ and $B_{s}$, i.e., an excess of newly marked breeders that were never recaptured (Table 1). Moreover, there was an indication that some European Storm Petrels were captured or present more often than others, i.e., a trap-dependence effect (Table 1): we consequently considered specific parameters, noted $m$, for consecutive recaptures for Storm Petrels (denoted by subscript $\mathrm{p})$. The more general models $\left\{\phi_{\mathrm{p}}^{\prime}(t+c+t . c)\right.$ $\left.\phi_{\mathrm{p}}(t+c+t . c) p_{\mathrm{p}}(m+t+c+t . m+c . m+t . c+m . t . c)\right\}\left(\chi^{2}=\right.$ 35.98, df $=26 . P=0.090$; scale parameter $\hat{c}=1.53)$ and, for shearwaters (subscript s), $\left\{\phi_{\mathrm{s}}^{\prime}(t+c+t . c) \phi_{\mathrm{s}}(t+c+\right.$ t.c) $\left.p_{\mathrm{s}}(t+c+t . c)\right\}\left(\chi^{2}=28.94, \mathrm{df}=29, P=0.283\right.$; scale parameter $\hat{c}=1.06$; Table 1) were used as starting point for the analyses. We began model selection for Storm Petrels by testing the interaction terms in the probability of recapture (models 1-6 in Appendix B). None of these were significant and a trap-dependence effect was significant in colony $A_{p}$ only (models 2 and 3 in Appendix B). The probability of recapture in colony $\mathrm{B}_{\mathrm{p}}$ increased linearly over time (model 6 in Appendix B). $A$ further reduction in the $\mathrm{QAIC}_{\mathrm{c}}$ value was obtained by assuming a constant and common adult survival probability for resident birds in $\mathrm{A}_{\mathrm{s}}$ and $\mathrm{B}_{\mathrm{s}}$ (model 8; Appendix B). In contrast, a time effect on survival of first-seen animals in colony $A_{p}$ was retained (models 9 and 11; Fig. 2a). The percentage of the variance explained by a colony-by-time interaction was $77 \%$ (models 10-12). Although model 8 had a low $\Delta$ QAIC $_{c}$ value, there was evidence that the local adult survival of resident birds changed over colonies when this effect was retested in the presence of a time-varying recapture probability in colony $A_{s}$ (models 17 and 18), which was dropped in an earlier stage of the model selection. Model averaging of these models yielded survival estimates of $0.781 \pm 0.019$ (mean \pm SE) and $0.690 \pm 0.036$ ) for colony $A_{p}$ and $B_{p}$, respectively. Surprisingly, the colony
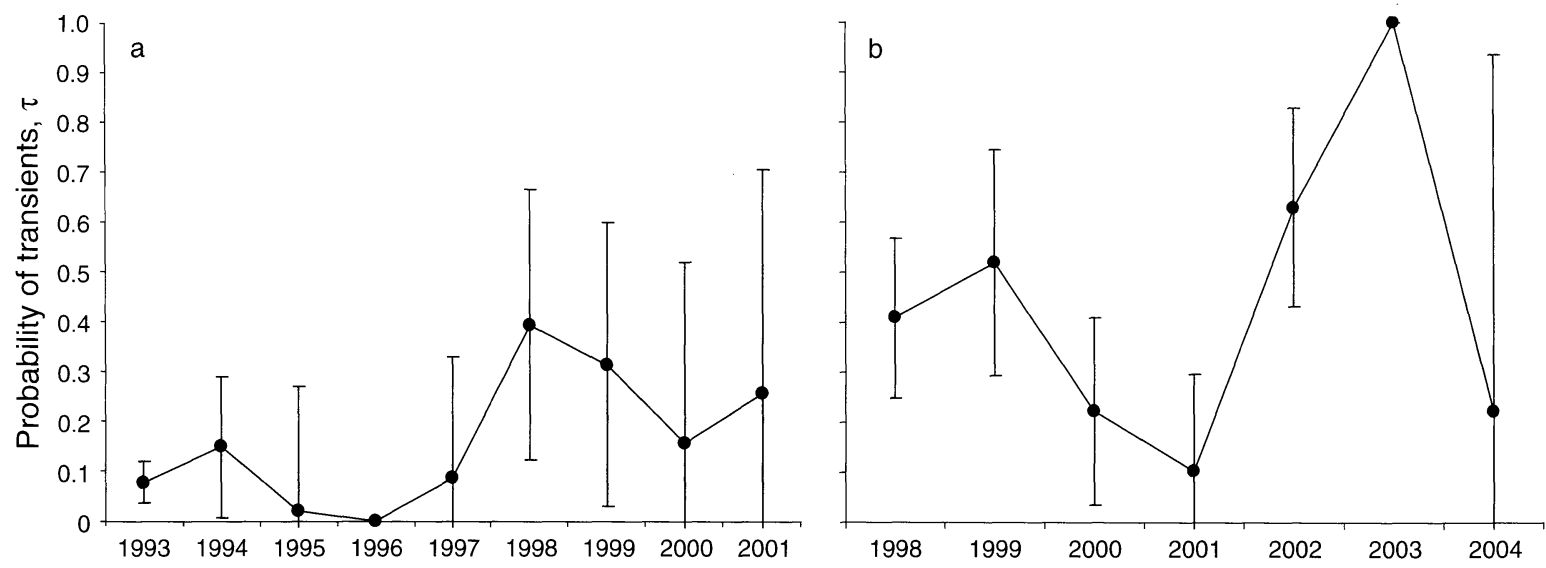

FIg. 2. Mean proportion (and 95\% confidence interval) of transients ( $\tau$ ), i.e., breeders that do not settle, for (a) European Storm Petrels and (b) Balearic Shearwaters in colonies $A_{p}$ and $B_{s}$, respectively, with variation over time in both cases. 
TABLE 2. QAIC values of models for the estimation of breeding parameters.

\begin{tabular}{lcrrrrrrr}
\hline \hline \multirow{2}{*}{ Effects } & \multicolumn{2}{c}{ European Storm Petrel success } & & \multicolumn{2}{c}{ Balearic Shearwater success } \\
\cline { 2 - 3 } & Hatching & Fledging & Breeding & & Hatching & Fledging & Breeding \\
$t+c+t . c$ & $\mathbf{2 0 7 1 . 2 5}$ & $\mathbf{9 6 1 . 0 0}$ & $\mathbf{2 0 7 4 . 6 2}$ & & 689.22 & 211.90 & 683.76 \\
$t+c$ & 2078.25 & 986.90 & 2098.92 & & $\mathbf{6 8 6 . 4 1}$ & $\mathbf{2 0 6 . 6 0}$ & $\mathbf{6 7 8 . 2 3}$ \\
$c$ & 2190.72 & 1002.40 & 2199.39 & & 690.35 & $\mathbf{2 0 6 . 8 0}$ & $\mathbf{6 7 9 . 8 8}$ \\
$t$ & 2076.25 & 986.40 & 2096.92 & & $\mathbf{6 8 4 . 4 1}$ & $\mathbf{2 0 4 . 6 0}$ & $\mathbf{6 7 6 . 2 3}$ \\
- & 2188.70 & 1001.90 & 2197.39 & & 688.43 & $\mathbf{2 0 5 . 1 0}$ & $\mathbf{6 7 7 . 8 8}$ \\
$\hat{c}$ & 1.28 & 1.00 & 1.30 & & 1.26 & 1.00 & 1.31 \\
\hline
\end{tabular}

Notes: Model notation includes $t$, time; $c$, colony; $t . c$, interaction between $t$ and $c$; and -, constant. The overdispersion parameter $\hat{c}$ is used to scale model deviance for each species. Retained models (those within 4 AIC points of the lowest AIC value) are in boldface.

with higher adult survival was the one with higher predation by Yellow-legged Gulls but with a significant lower survival for first-seen birds, i.e., transients.

Results for the Balearic Shearwaters were similar. The first models indicated a significant interaction in the probability of recapture between the colony and time effects (models 19-23 in Appendix B). In particular, recapture probability varied significantly over time in colony $\mathrm{A}_{\mathrm{s}}$ but not in colony $\mathrm{B}_{\mathrm{s}}$. When transient and resident birds in colony $B_{s}$ were assumed to have the same survival, the colony-by-time interaction explained $23 \%$ of the spatiotemporal variation in survival and models assuming a common pattern of variation across colonies were rejected (models 24-26, Appendix B). This colony-dependent pattern was caused by the presence of transients in colony $\mathrm{B}_{\mathrm{s}}$. Indeed, resident birds in colony $\mathrm{B}_{\mathrm{s}}$ and birds breeding in colony $\mathrm{A}_{\mathrm{s}}$ had a similar pattern of variation in survival (model 26), but this pattern was not retained for transient birds (model 27). Again, the retained model (model 27) includes a time-by-colony interaction term due to a variable transience probability, even though the colonies were free of predators. From the model assuming an average value of survival in both colonies (model 30 ), the survival probability was 0.807

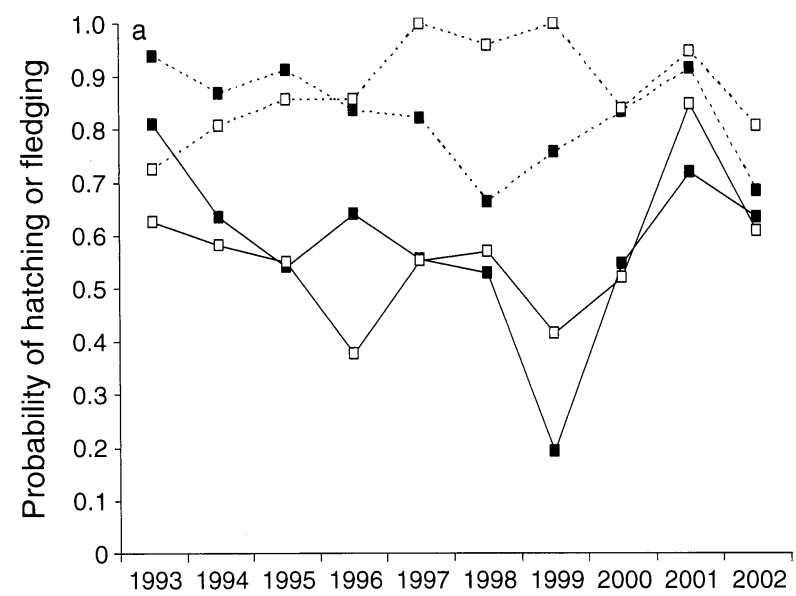

$\pm 0.02\left(\right.$ mean $\pm \mathrm{SE}$ ) for colony $\mathrm{A}_{\mathrm{s}}$ and $0.662 \pm 0.04$ for resident birds in colony $B_{s}$. As for Storm Petrels, adult survival probability of first-seen birds in colony $B_{s}$ (i.e., transients) was changing with time (Fig. 2b), but in this case the colony with lower adult survival was also the one with transients.

\section{Breeding parameters}

The average breeding success was very similar between the two colonies for both species $(0.49$ and 0.51 for Storm Petrels and 0.62 for the two colonies of Balearic Shearwaters). Despite the similarity of average values, the interaction between colony and year effects was significant for European Storm Petrels $(\triangle \mathrm{QAIC}=$ 24.3; Table 2, Fig. 3a): colony $B_{p}$ had a lower breeding success than colony $A_{p}$ between 1993 and 1996, but reversing in 1997. The percentage of the total deviance explained by the interaction between year and colony on the breeding success was $26 \%$, but this varied from $16 \%$ for the hatching success to $57 \%$ for the fledging success. In contrast, the breeding success of the Balearic Shearwater was constant over time and colonies (Table 2, Fig. 3b). For the Storm Petrel, the interaction between year and colony was again significant for hatching and

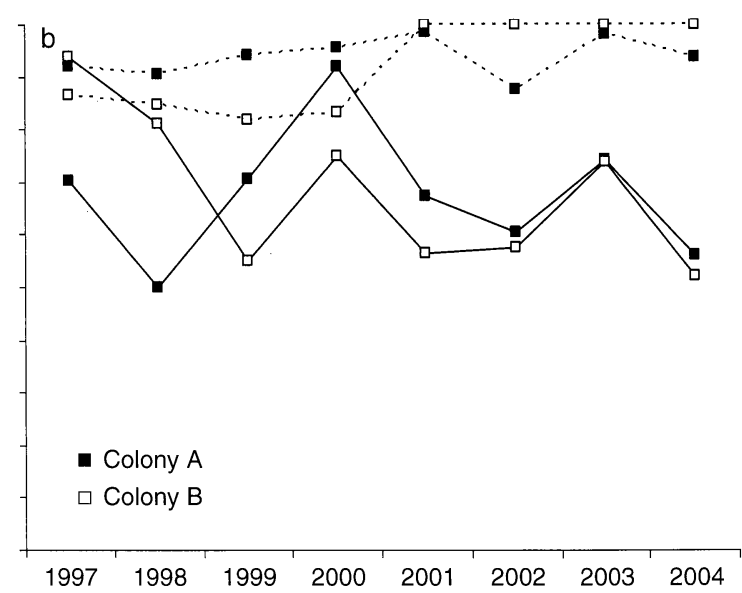

FIG. 3. Changes in hatching (solid lines) and fledging (dashed lines) probabilities according to colony and year for (a) European Storm Petrels and (b) Balearic Shearwaters. Note that fledging probability was conditional to hatching. For the Storm Petrel, colony A had greater values until 1996, but the trend reversed afterward, causing the interaction term between year and colony to be retained during model selection. For the Balearic Shearwater, variations in hatching or breeding success were not significant. 
fledging success $(\triangle \mathrm{QAIC}=7.0$ and 16.3 , respectively; Fig. 3a). This effect explained a similar percentage of the total deviance $(38 \%)$ in both, hatching and fledging success. In larger colonies the hatching success was more variable than the fledging success (Table 3 ), but these two components showed similar variation in the smaller colonies.

\section{Matrix modeling analysis}

The estimated yearly population growth rates of both colonies were not correlated either for European Storm Petrels or for Balearic Shearwaters (Kendall's rank correlation coefficient $=0.11, P=0.76$; and Kendall's correlation coefficient $=0.33, P=0.38$, respectively). This difference persisted for the Storm Petrel even when transients were not considered.

\section{DiscusSiON}

Results suggest that adult survival was mainly time invariant, but, unexpectedly, it was different at each colony of both species. Although the general theory and empirical examples have showed that long-lived birds exhibit constant adult survival (Lebreton 2001, Tavecchia et al. 2001, Weimerskirch 2002), there is recent evidence that this parameter may change steadily in time and space, even at neighboring colonies, influenced by local factors such as food availability or predator density (Cam et al. 2004, Frederiksen et al. 2005). Nevertheless, the colony-specific survival at two adjacent sites found here was difficult to interpret. For Storm Petrels, adult survival was strikingly higher in the colony with higher predation rates (and the only one with a transient effect, probably brought about by predators); for Balearic Shearwaters, this result was even more unexpected because both study colonies were free of predators. The presence of large numbers of transient animals at one colony of each species was an additional emergent feature of the present study; their influence in population dynamics seldom has been described (but see Perret et al. 2003, Cam et al. 2004), and most of the time it has been related to juveniles that disperse from the study site before breeding or to erratic animals that do not breed (e.g., Clark et al. 2004). Furthermore, transients varied stochastically with time (Oro et al. 1999). Again, although increased predation by the Yellow-legged Gull on Storm Petrels could explain the existence of transients (Oro et al. 2005), other unknown factors should drive the same phenomenon in the Balearic Shearwater. Independently of the local causes, a high apparent mortality or permanent emigration of first-seen animals can be demographically significant (Oro et al. 1999, Perret et al. 2003) and strong enough to drive close populations into asynchronous fluctuations.

Breeding parameters of the two species varied significantly over time, although this variation was less pronounced for the Balearic Shearwater. For the European Storm Petrel, the interaction between year and colony was significant for hatching and fledging
TABLE 3. Relativized coefficients of variation, CVr, of hatching and fledging success.

\begin{tabular}{|c|c|c|c|c|}
\hline \multirow[b]{2}{*}{ Colony } & \multicolumn{2}{|c|}{$\begin{array}{l}\text { European Storm } \\
\text { Petrel success }\end{array}$} & \multicolumn{2}{|c|}{$\begin{array}{c}\text { Balearic Shearwater } \\
\text { success }\end{array}$} \\
\hline & Hatching & Fledging & Hatching & Fledging \\
\hline A & 0.33 & 0.25 & 0.27 & 0.15 \\
\hline B & 0.26 & 0.28 & 0.32 & 0.32 \\
\hline
\end{tabular}

Note: For details on calculation of CVr, see Methods.

success (Fig. 3). This result was unexpected and cannot be related to yearly food availability, which, given the close proximity, must be the same for both colonies. The breeding success in the Balearic Shearwater varied over time but it was constant over time and space. The different pattern between species could be the result of different predation rates, affecting the petrels but not the shearwaters. In the absence of predation, populations sharing the same foraging grounds should show similar breeding parameters (but see Lambrechts et al. 2000, $\mathrm{Nel}$ et al. 2002, Genovart et al. 2003). There are two common features in our results that appear to be linked with colony size. First, resident birds in larger colonies have higher local survival than resident birds in small colonies. Second, variation in breeding success occurred mainly because of variation in the probability of hatching. This component of breeding success varies the most in larger colonies, probably due to the greater interindividual variability. Overall, our results showed that, in contrast with general theoretical predictions and empirical examples in many different organisms (Weatherhead et al. 2002, Johnson et al. 2005, Schaub et al. 2005), adjacent populations can exhibit asynchronous dynamics (see also Weimerskirch et al. 1997, Sagar et al. 1999, Frederiksen et al. 2005). The pattern of variation in adult survival, transience probability, and breeding output at each study colony seemed large enough to generate asynchronous dynamics in both species, at least in the short term. This is remarkable, because adult survival in Procellariiformes is nearly time invariant, probably due to environmental canalization of life history traits (see Gaillard and Yoccoz 2004) as natural selection tends to reduce the variability of the parameters that contribute the most to individual fitness (Morris and Doak 2004). The probability of survival of the resident birds was invariant over time in both species. At population level, however, the presence of transients induced a change in survival over time in at least one colony of both species that induces asynchrony. Nevertheless the nonsignificant association between population growth rates should be interpreted with caution due to the several non-estimated parameters (e.g., recruitment, juvenile survival), which were assumed to be the same for both colonies (Appendix C) Moreover, the period of time considered here was relatively short and, in this case, a small number of years with contrasting population trend may be sufficient to disrupt the association between population 
growth rates. Our study focused on small-scale processes and we cannot exclude synchrony at larger spatial or temporal scale. Nevertheless, our findings suggest that differences in demographic processes, mediated by local habitat or individual characteristics, can generate unexpected patterns of population synchrony.

\section{ACKNOWLEDGMENTS}

We formally acknowledge the many people who participated in the fieldwork over the years. We are also indebted to Beatriz Morales for logistic support. The study has been partially funded by grants from the Spanish Ministry of Science and Technology (ref. BOS2003-01960 and CGL2006-04325/BOS), the Balearic Government, and the European Commission (LIFE Program and DISCBIRD project). We are indebted to the wardens and Environmental Monitoring Service of Benidorm Island (Generalitat Valenciana). Steve Votier and Jason Gilchrist provided valuable comments on an early version of the manuscript. Many thanks also to Ana Sanz, Stephanie Jenouvrier, and an anonymous referee for their helpful suggestions. Thanks also to Remi Choquet and Roger Pradel for their help with Appendix A. Additional funds from the Biotechnology and Biological Sciences Research Council (BBSRC) and the "Ramon y Cajal" project were provided to G. Tavecchia during editing.

\section{Literature Cited}

Arcos, J. M., and D. Oro. 2004. Pardela Balear, Puffinus mauretanicus. Pages 46-50 in A. Madroño, C. González, and J. C. Atienza, editors. Libro Rojo de las Aves de España. Dirección. General para la Biodiversidad-SEO/BirdLife, Madrid, Spain.

Bjørnstad, O. N., R. A. Ims, and X. Lambin. 1999. Spatial population dynamics: analyzing patterns and processes of population synchrony. Trends in Ecology and Evolution 14 $427-432$.

Blasius, B., and L. Stone. 2000. Nonlinearity and the Moran effect. Nature 406:846-847.

Burnham, K. P., and D. R. Anderson. 1998. Model selection and inference. A practical information-theoretic approach. Springer-Verlag, New York, New York, USA.

Cam, E., D. Oro, R. Pradel, and J. Jimenez. 2004. Assessmen of hypotheses about dispersal in a long-lived seabird using multistate capture-recapture models. Journal of Animal Ecology 73:723-736.

Case, T. J. 2000. An illustrated guide to theoretical ecology. Oxford University Press, Oxford, UK.

Caswell, H. 2001. Matrix population models. Second edition. Sinauer, Sunderland, Massachusetts, USA.

Cattadori, I. M., D. T. Hydon, and P. J. Hudson. 2005 Parasites and climate synchronize red grouse populations. Nature 433:737-741.

Choquet, R., A.-M. Reboulet, J.-D. Lebreton, O. Gimenez, and R. Pradel. 2005. U Care2.2: User's manual. CEFE-CNRS, Montpellier, France. $\langle$ http://www.cefe.cnrs.fr/biom/logiciels. htm $>$

Choquet, R., A.-M. Reboulet, R. Pradel, and J.-D. Lebreton 2000. U_Care1.4: User's guide. CEFE-CNRS, Montpellier, France. $\langle$ http://www.cefe.cnrs.fr/biom/logiciels.htm $\rangle$

Clark, R. G., K. A. Hobson, J. D. Nichols, and S. Bearhop. 2004. Avian dispersal and demography: scaling up to the landscape and beyond. Condor 106:717-719.

Frederiksen, M., M. P. Harris, and S. Wanless. 2005. Interpopulation variation in demographic parameters: a neglected subject? Oikos 111:209-214

Gaillard, J.-M., and N. G. Yoccoz. 2004. Temporal variation in survival of mammals: a case of environmental canalization. Ecology 84:3294-3306.
Genovart, M., L. Jover, X. Ruiz, and D. Oro. 2003. Offspring sex ratio in subcolonies of Audouin's gull, Larus audouinii, with differential breeding performance. Canadian Journal of Zoology 81:905-910

Grenfell, B. T., K. Wilson, B. F. Finkenstädt, T. N. Coulson, S. Murray, S. D. Albon, J. M. Pemberton, T. H. Clutton-Brock and M. J. Crawley. 1998. Noise and determinism in synchronized sheep dynamics. Nature 394:674-677.

Harris, M. P., T. Anker-Nilssen, R. H. McCleery, K. E Erikstad, D. N. Shaw, and V. Grosbois. 2005. Effect of wintering area and climate on the survival of adult Atlantic puffins Fratercula arctica in the eastern Atlantic. Marine Ecology Progress Series 297:283-296.

Ims, R. A., and H. P. Andreassen. 2000. Spatial synchronization of vole population dynamics by predatory birds. Nature 408:194-196.

Johnson, M. D., T. W. Sherry, A. M. Strong, and A. Medori. 2005. Migrants in Neotropical bird communities: an assess ment of the breeding currency hypothesis. Journal of Anima Ecology 74:333-341.

Koenig, W. 1999. Spatial autocorrelation of ecological phenomena. Trends in Ecology and Evolution 14:22-26.

Lambrechts, M. M. P. Perret, M. Maistre, and J. Blondel. 2000. Do experiments with captive non-domesticated animals make sense without population field studies? A case study with blue tits' breeding time. Proceedings of the Royal Society of London B 266:1311-1315.

Lande, R., S. Engen, and B.-E. Sæther. 2003. Stochastic population dynamics in ecology and conservation. Oxford University Press, Oxford, UK

Lebreton, J.-D. 2001. The use of bird rings in the study of survival. Ardea 89:85-100.

Lebreton, J.-D., K. P. Burnham, J. Clobert, and D. R. Anderson. 1992. Modeling survival and testing biological hypotheses using marked animals: a unified approach with case studies. Ecological Monographs 62:67-118.

Lebreton, J.-D., and J. Clobert. 1991. Bird population dynamics, management, and conservation: the role of mathematical modelling. Pages $105-125$ in C. M. Perrins, J.-D. Lebreton, and G. J. M. Hirons, editors. Bird population studies, relevance to conservation and management. Oxford University Press, Oxford, UK.

Lecomte, J., K. Boudjemandi, F. Sarrazin, K. Cally, and J. Clobert. 2004. Connectivity and homogenisation of population sizes: an experimental approach in Lacerta vivipara Journal of Animal Ecology 73:179-189.

Liebhold, A., W. D. Koenig, and O. N. Bjørnstad. 2004a Spatial synchrony in population dynamics. Annual Review of Ecology, Evolution, and Systematics 35:467-490.

Liebhold, A., V. Sork, M. Peltonen, W. D. Koenig, O. N Bjørnstad, R. Westfall, J. Elkinton, and J. M. H. Knops $2004 b$. Within-population spatial synchrony in mast seeding of North American oaks. Oikos 104:156-164.

Lloyd, A. L., and R. M. May. 1999. Synchronicity, chaos and population cycles: spatial coherence in an uncertain world. Trends in Ecology and Evolution 14:417-418.

Mínguez, E., and D. Oro. 2003. Variations in nesting mortality in the European storm petrel Hydrobates pelagicus. Ardea 91 113-117.

Moran, P. A. P. 1953. The statistical analysis of the Canadian lynx cycle. II. Synchronization and meteorology. Australian Journal of Zoology 1:291-298.

Morgan, B. J. T. 2000. Applied stochastic modelling. Arnold, London, UK.

Morris, W. F., and D. F. Doak. 2004. Buffering of life-histories against environmental stochasticity: accounting for a spurious correlation between the variabilities of vital rates and their contributions to fitness. American Naturalist 165:579590

Nel, D. C., P. G. Ryan, J. L. Nel, N. T. W. Klages, R. P Wilson, G. Robertson, and G. N. Tuck. 2002. Foraging 
interactions between Wandering Albatrosses Diomedea exulans breeding on Marion Island and long-line fisheries in the southern Indian Ocean. Ibis 144:E141-E154.

Oro, D., J. S. Aguilar, J. M. Igual, and M. Louzao. 2004a. Modelling demography and extinction risk in the endangered Balearic shearwater. Biological Conservation 116:93-102.

Oro, D., E. Cam, R. Pradel, and A. Martínez-Abraín. 2004b. Influence of food availability on demography and loca population dynamics in a long-lived seabird. Proceedings of the Royal Society of London B 271:387-396.

Oro, D., A. De León, E. Minguez, and R. W. Furness. 2005 Estimating predation on breeding European Storm-petrels by yellow-legged gulls. Journal of Zoology 265:1-9.

Oro, D., R. Pradel, and J.-D. Lebreton. 1999. Food availability and nest predation influence life history traits in Audouin's gull, Larus audouinii. Oecologia 118:438-445.

Paradis, E., S. R. Baillie, W. J. Sutherland, and R. D. Gregory. 1999. Dispersal and spatial scale affect synchrony in spatia population dynamics. Ecology Letters 2:114-120.

Perret, N., R. Pradel, C. Miaud, O. Grolet, and P. Joly. 2003. Transience, dispersal and survival rates in newt patchy populations. Journal of Animal Ecology 72:567-575.

Pfister, C. A. 1998. Patterns of variance in stage-structured populations: evolutionary predictions and ecological implications. Proceedings of the National Academy of Sciences (USA) 95:213-218.

Pollock, K. H., J. D. Nichols, C. Brownie, and J. Hines. 1990 Statistical inference for capture-recapture experiments. Wildlife Monographs 107.

Pradel, R. 1993. Flexibility in survival analysis from recapture data: handling trap-dependence. Pages 29-37 in J.-D Lebreton and P. M. North, editors. Marked individuals in the study of bird population. Birkhauser Verlag, Basel, Switzerland.

Pradel, R. 1996. Utilization of capture-mark-recapture for the study of recruitment and population growth rate. Biometrics 52:703-709.

Pradel, R., O. Gimenez, and J.-D. Lebreton. 2005. Principles and interest of GOF tests for multistate capture-recapture models. Animal Biodiversity and Conservation 28:189-204.

Pradel, R., J. E. Hines, J.-D. Lebreton, and J. D. Nichols. 1997a. Capture-recapture survival models taking account of transients. Biometrics 53:60-72.

Pradel, R., N. Rioux, A. Tamisier, and J.-D. Lebreton. $1997 b$. Individual turnover among wintering teal in Camargue: a mark-recapture study. Journal of Wildlife Management 61: 816-821.

Ranta, E., V. Kaitala, J. Lindström, and H. Lindén. 1995. Synchrony in population dynamics. Proceedings of the Royal Society of London B 262:113-118.
Ruetz, C. R., J. C. Trexler, F. Jordan, W. F. Loftus, and S. A. Perry. 2005. Population dynamics of wetland fishes: spatiotemporal patterns synchronized by hydrological disturbance? Journal of Animal Ecology 74:322-332.

Sagar, P. M., J.-C. Stahl, J. Molloy, G. A. Taylor, and A. J. D. Tennyson. 1999. Population size and trends within the two populations of Southern Buller's Albatross, Diomedea bulleri bulleri. Biological Conservation 89:11-19.

Schaub, M., W. Kania, and U. Köppen. 2005. Variation of primary production during winter induces synchrony in survival rates in migratory white storks Ciconia ciconia. Journal of Animal Ecology 74:656-666.

Stenseth, N. C., K. S. Chan, H. Tong, R. Boonstra, S. Boutin C. J. Krebs, E. Post, M. O'Donoghue, N. G. Yoccoz, M. C. Forchhammer, and J. W. Hurrell. 1999. Common dynamic structure of Canada lynx populations within three climatic regions. Science 285:1071-1073.

Sutcliffe, O. L., D. C. Thomas, and D. Moss. 1996. Spatial synchrony and asynchrony in butterfly dynamics. Journal of Animal Ecology 65:85-95.

Tavecchia, G., R. Pradel, V. Boy, A. Johnson, and F. Cézilly. 2001. Sex- and age-related variation in survival and cost of first reproduction in Greater Flamingos. Ecology 82:165-174.

Vik, J. O., N. C. Stenseth, G. Tavecchia, A. Mysterud, and O. C. Lingjaerde. 2004. Living in synchrony on Greenland coasts? Nature 427:697-698.

Warham, J. 1990. The petrels. Their ecology and breeding systems. Academic Press, London, UK.

Weatherhead, P. J., G. Blouin-Demers, and K. A. Prior. 2002. Synchronous variation and long-term trends in two populations of black rat snakes. Conservation Biology 16:16021608

Weimerskirch, H. 2002. Seabird demography and its relationship with the marine environment. Pages 115-135 in E. A Schreiber and J. Burger, editors. Biology of marine birds. CRC Press, New York, New York, USA.

Weimerskirch, H., N. Brothers, and P. Jouventin. 1997. Population dynamics of wandering albatross Diomedea exulans and Amsterdam albatross D. amsterdamensis in the Indian Ocean and their relationships with long-line fisheries: conservation implications. Biological Conservation 79:257270

White, G. C., and K. P. Burnham. 1999. Program MARK: survival estimation from populations of marked animals Bird Study 46(Supplement): 120-129.

Williams, B. K., J. D. Nichols, and M. J. Conroy. 2002 Analysis and management of animal populations. Academic Press, San Diego, California, USA.

\section{APPENDIX A}

Verifying capture-recapture assumptions (Ecological Archives E089-006-A1).

APPENDIX B

Modeling survival and encounter probability (Ecological Archives E089-006-A2).

APPENDIX C

Species- and colony-specific population matrix models (Ecological Archives E089-006-A3). 